\title{
Blockchain and Supply Chain Management: A New Paradigm for Supply Chain Integration and Collaboration
}

\author{
Michael Wang \\ Faculty of Engineering Technology and Science, \\ Higher Colleges of Technology, Abu Dhabi, United Arab Emirates \\ Email: michael.wang@hct.ac.ae (Corresponding Author) \\ Yong Wu \\ Department of Business Strategy and Innovation, \\ Griffith University, Brisbane, Australia \\ Email: yong.wu@griffith.edu.au
}

\author{
Bruce Chen \\ Department of Data Science and Artificial Intelligence, \\ Faculty of Information Technology, Monash University, Melbourne, Australia \\ Email: bruce.ying.chen@monash.edu \\ Melissa Evans \\ Forest Informatics, \\ Scion (The New Zealand Forest Research Institute), Rotorua, New Zealand \\ Email: melissa.evans@scionresearch.com
}

\begin{abstract}
Despite there are some arguments about blockchain, it has been highlighted as an important distributed secure technology in the $21^{\text {st }}$ century. It is an incorruptible digital ledger of economic transactions that can be programmed to record not just financial transactions but virtually everything of value. Dobrovnik et al. (2018) suggest that blockchain is a revolutionising technology that would change industries at an international level, add values to firms and supply chain networks, improve commerce, and drive economy. Although blockchain has attracted attentions, very few blockchain studies have been focussed on supply chain integration and collaboration areas. This study illustrates the possibilities of applying blockchain technology in the coordination of activities for effective and efficient supply chain management. The study takes a closer look at the use of blockchain in supply chains beyond cryptocurrency, payment, and finance via the use of smart contract and consensus algorithm (i.e., imposing constraints). The key attributes of blockchain are discussed and potential questions were identified in New Zealand. The expected outcome of this study will advance the understanding of the blockchain and supply chain literature, besides inspire both researchers and practitioners to consider the use of blockchain in different context-aware future studies.
\end{abstract}

Keywords: blockchain, supply chain, technology, supply chain integration, industry 4.0

\section{INTRODUCTION}

The blockchain technology is an important distributed secure technology in the prevailing Industry 4.0 era of today and has attracted great attention from both academia and industry (Dobrovnik et al., 2018; Swan, 2017). Blockchain is known as distributed ledger technology (Tschorsch and Scheuermann, 2016; Zyskind et al., 2015), which allows participants to secure the settlement of transactions, archive the transaction, and transfer assets at a low-cost (Tschorsch and Scheuermann, 2016). It is not only a new type of internet infrastructure based on distributed applications but also a new type of supply chain network, which may provide a new paradigm for future business (Hackius and Petersen, 2017; Mansfield-Devine, 2017; Swan, 2015). As an emerging technology, a lot of revolution and research have just begun regarding this distributed technology.

A growing number of products are delivered to the customers through supply chains that are composed of independent firms (Christopher and Peck, 2012; Wang et al., 2018). As a result, today's businesses do not only compete as isolated companies, but also as part of a large supply chain network (Christopher, 2005; Wang et al., 2015). Companies face increased uncertainty, challenges, and constraints, due to globalization, higher customer expectation, market competition, supply chain complexity and uncertainty, which call for coordination and cooperation across the supply chains (inter- and intra- supply chains) and the needs 
for information technology (Huddiniah and Er, 2019). However, supply chains often are fragmented with internal competition, limited information exchange and price negotiations occurring behind closed doors in New Zealand (Bezuidenhout, 2017). In addition, these constraints directly influence the business performance and often result in challenges and constraints, such as high operation costs or capacity shortage, which could be resolved by the Blockchain revolution (Tapscott and Tapscott, 2016).

This paper attempts to explore blockchain applications in supply chain management and investigate the relationship between blockchain and supply chain collaboration and integration. Based on the Socio-Technical Theory (STT), technology is an important variable to optimise the process, task, structure (Bostrom and Heinen, 1977). STT consists of two systems, namely the social system and the technical system. At the time when this study started in mid-2018 to explore the use of new technologies in the New Zealand industry 4.0 era, there was a paucity of blockchain research conducted in the New Zealand context. We narrowed down the scope of the research by focusing on the technical system, which is concerned with the processes, tasks and technology needed to transform inputs to outputs (Cartelli, 2007). Blockchain shows a huge potential to reconfigure the task structure and manage the constraints in supply chains (Cole et al., 2019). Nevertheless, there have been very few studies conducted on the nexus between blockchain and supply chain integration and collaboration (Bai and Sarkis, 2020; Chang and Chen, 2020). Therefore, this paper tries to fill this research gap by focusing on the following two main research questions:

RQ1: What are the key attributes of blockchain technology applicable to supply chain management?

RQ2: How does the blockchain technology enable the supply chain integration and collaboration?

To answer the research questions, a qualitative research is designed in this study. We used both desk research and informal interview techniques to tackle the questions to ensure the research reliability and validity. First, we reviewed the relevant literature, previous studies, and business cases in blockchain and supply chain and extracted the important attributes of blockchain. Then, informal interviews were conducted to verify the results in New Zealand industries. In addition, we asked the interviewees whether they feel that the blockchain technology could help their business to improve the integration and collaboration in a supply chain. Over $80 \%$ of the respondents provided positive feedback regarding the blockchain technology. The results may demonstrate the practical implications of blockchain for supply chain management, by shedding light on supply chain integration and collaboration.

The rest of the paper is organised as follows. Section 2 describes the relevant literature and background information. Section 3 briefly introduces the research methods and Section 4 presents the research results. Section 5 discusses the important practical features and potential challenges. Finally, Section 6 concludes the paper with further research directions.

\section{BACKGROUND}

\subsection{What's Blockchain?}

Blockchain is a decentralized digital ledger that can be programmed to distribute and store data. It is also known as a distributed ledger, which is based on a peer-to-peer (P2P) or decentralized network, consisting of a continuous sequence of blocks. Swan (2017) suggests that the terms blockchains and digital ledgers are generally interchangeable. In a blockchain network, all the parties can simultaneously share and record the blocks, which must be verified and validated by all users in the network. Blocks are linked by the cryptographic hash function. Every transaction is trackable by examining the block information linked by hash keys (Chen et al., 2018; Zheng et al., 2018; Zheng et al., 2017). Blockchain advocates claim transparency, speed, accessibility and non-falsifiability as the cornerstones of this new paradigm (Apte and Petrovsky, 2016). Sultan and Lakhani (2018) suggest that the blockchain is a decentralised database containing sequential, cryptographically linked blocks of digitally signed asset transactions, governed by a consensus model.

All ledgers are encrypted and uploaded to block network with a timestamp, hence all blocks are integrated with time sequence as the whole book. Apparently, if a user wants to change the record, s/he must adjust the entire book records, because blockchain utilises distributed database storing all data, and the core concept of blockchain is distributed computing instead of centralisation. In other words, it will not work if hackers only change information on one block.

Distributed computing not only saves cost of calculating, it also solves the data security issue as all participators have the same "book". In addition, in a blockchain, every node transfers data by using P2P approach to reduce the cost of achieving decentralization. Given there is not a centralize server, all data are distrusted and stored in individual computers, therefore organization cannot change any data without consensus across the whole blockchain network. On the contrary, when there is a new transaction in the whole network, everyone will verify and add it into their "books" (Swan, 2015).

Although the blockchain technology is relatively new, there have been three generations of blockchains including the Blockchain 1.0, which is the core technology used to create the cryptocurrencies, such as Bitcoin, Litecoin, etc. The first generation blockchain appeared in 2009, as a part of Bitcoin, and provided a technique for an incorruptible digital ledger of economic transactions. In 2015, Ethereum used an improved blockchain 2.0 for validating transactions. The Blockchain 2.0 was developed from the decentralised digital ledger, which includes many different categories, such as the Blockchain 2.0 protocols, smart contracts and decentralised application. With the development of computer technology, the blockchain 2.0 protocols can be used to manage not just financial transactions but virtually everything of value. The Blockchain 2.0 space is still in development, many Blockchain 2.0 projects are mainly applied for the transferring of all kinds of assets beyond currency using the blockchain (Swan, 2015). The primary argument for Blockchain 1.0 and 2.0 transactions is the economic efficiency and cost savings afforded by trustless interactions in decentralized network models. Blockchain 
3.0 is still emerging. Yli-Huumo et al. (2016) and Garrod (2016) argue that the future research directions for blockchain are not clear. We may consider blockchain as a new paradigm, which is a decentralised network for supply chain integration and collaboration beyond currency, payment, and economics.

\subsection{Supply Chain Integration and Collaboration}

Supply chain management is the integration of material, information, and financial flows in a network of companies or organisations. Multiple supply chain partners need to work together collaboratively to make and deliver products and services to the consumer. Supply chain management concept fundamentally changes the nature of a firm as control is no longer based on direct control of the internal business processes, but rather based on integration across member organisations in the supply chain (Lai et al., 2004; Porter, 2019).

Supply chain collaboration is considered as an important factor to achieve a win-win solution for different shareholders in a supply chain (Ramanathan and Gunasekaran, 2014; Tsou, 2013). Moreover, Soosay and Hyland (2015) stress that collaboration goes beyond integration by including long-term commitments to technology sharing and to closely integrated planning and control systems. There are different forms of supply chain collaboration including collaborative planning, collaborative decision making and collaborative execution (Ramanathan and Gunasekaran, 2014). Supply chain collaboration requires a high level of commitment, trust, joint decisions and information sharing (Liao et al., 2017; Pradabwong et al., 2017; Soosay and Hyland, 2015; Zhang and Cao, 2018). Supply chain integration includes internal, external, supplier and customer integration (Alfalla-Luque et al., 2015; Flynn et al., 2010; Kim, 2006; Maiga, 2016). A high level of supply chain integration and collaboration lead to higher levels of supply chain performance (Chen et al., 2017; Wiengarten $e t$ al., 2016).

In this paper, we consider the supply chain integration and collaboration as a firm's capability to sense, collaborate, coordinate and reconfigure the elements in a supply chain including internal cross-functional integration and external integration with suppliers and customers. Hafeez et al. (2002) regard capability as the ability to make use of resources to perform some task or activity; they define a resource as anything, tangible or intangible, owned or acquired by a firm including technology. In this sense, blockchain can be understood as a technology to facilitate the firm's ability, e.g., ability of integration and collaboration from a resource-based view (RBV) in this study.

\section{METHODOLOGY}

We conducted a qualitative research to address the research questions. As part of the qualitative research design, an interpretive approach was employed to understand the important attributes of the blockchain for supply chain collaboration and integration. The interpretive approach requires the research scientist to grasp the subjective meaning of phenomenon and social action (Bryman, 2012). Mixed research methods including desk research, informal interview, and case study were applied in the study.
We first conducted a desk research to identify the key attributes of blockchain regarding supply chain management. This provided the basis for the informal interview and case study that were organised to verify and understand the relationships between key attributes and supply chain collaboration and integration. Because the informal interview was conducted in New Zealand, the case study was used to support the findings through international cases.

The Elsevier's Scopus, the largest abstract and citation database of peer-reviewed literature, was used as the main source for the literature review in this study. We tackled the first research question through a review of relevant literature and focused on two main areas: "blockchain" and "supply chain collaboration and integration". We used the search strings including "blockchain" AND "supply chain management" (296 articles); "blockchain" AND "attributes" (38 articles); "blockchain" AND "attribute" AND "supply chain" (5 articles); "blockchain" AND "supply chain collaboration" OR "supply chain integration" (10 articles) to search the article title, abstract, keyword in English journal articles, conference articles and scholarly material from 2015 to early 2020. The lists resulted from the search were reviewed, duplicate results removed, and articles that were not related to the Blockchain and supply chain integration and collaboration were discounted, which led to the final selection of 45 articles. The number of the published blockchain and supply chain management articles has been increased sharply since 2018, and the majority of the early published studies have very similar attributes. Thus, we did not cite all research articles in the results.

The informal interviews and international cases were used to verify the attributes extracted from desk research and indicate the current popular applications of blockchain in supply chains and how the blockchain can enable supply chain collaboration and integration. The informal interview was conducted in Rotorua, New Zealand. Seventeen senior managers, executives, CEOs and researchers were also approached during the HarvestTECH conferences and workshops during 26-27 June 2019. We asked them to choose the current Blockchain application in their organisations. The results revealed popular blockchain applications: information sharing, traceability and automation in digital transformation. Given the fact that there are very few companies using the blockchain in New Zealand, the sample size is considered as satisfactory. The international cases were applied to address the research questions to support and confirm the findings in New Zealand. This may imply that the blockchain enables the supply chain collaboration and integration.

\section{RESULTS}

In this section, we present the results including important attributes of blockchain and the popular practical applications of the blockchain in supply chain integration and collaboration.

\section{1 Important Attributes of the Blockchain}

The blockchain is considered as a powerful tool to improve the efficiency and effectiveness of business processes and transactions (Hackius and Petersen, 2017; Swan, 2015; Underwood, 2016). It is therefore essential to understand the attributes and/or functions which may be used 
to strengthen the capabilities and/or relationships among the business partners in supply chains and enhance the overall efficiency and effectiveness of supply chain performance. In this subsection, firstly, we review the previous studies and identify the key attributes of the blockchain technology; then we discuss the relationships between the attributes and supply chain integration and collaboration.

Digital ledgers offer some important attributes, which can be adopted in the supply chain (Dobrovnik et al., 2018; Hackius and Petersen, 2017; Swan, 2017; Tapscott and Tapscott, 2016). In previous studies, Jawaji et al. (2020) mention that Blockchain enforces transparency, security, authenticity, and auditability. Yang et al. (2019) investigate the attributes of blockchain including decentralization, security, visibility and trust in the iron and steel supply chains. Zheng et al. (2018) state that the key characteristics of a blockchain include decentralisation, persistency, anonymity, and auditability, and the important properties of a blockchain are decentralized, verified, and immutable. Sultan and Lakhani (2018) stress four core characteristics of blockchain: immutable, decentralised, consensus driven, and transparent. Chen et al. (2018) identify four features: decentralization, traceability, immutability, and currency properties from the technical point of view and advantages of blockchain technology including reliability, trust, security, and efficiency. Zyskind et al. (2015) stress that blockchain, which is a trusted, auditable and decentralized system, can be used to manage personal data. MansfieldDevine (2017) emphasises that trust is important for a business network, for which blockchain provides a kind of assurance that is cheaper and a standardised service for companies. Conte de Leon et al. (2017) argue that blockchain could offer higher service availability at much lower costs for some types of business and enterprise applications. In the literature, despite previous studies may have different names for an attribute, some attributes with similar names have been merged and summarised as the key attributes of a blockchain as presented in Table $\mathbf{1}$ below. Each of these key attributes is discussed accordingly in this section.

Table 1 Important attributes of a blockchain

\begin{tabular}{|c|c|c|}
\hline Attributes of a Blockchain & Explanation & Studies \\
\hline Immutable & $\begin{array}{l}\text { It also knowns as irreversibility. The data can } \\
\text { hardly be modified or deleted after the data has } \\
\text { been approved by all nodes in blockchain. }\end{array}$ & $\begin{array}{l}\text { Astarita et al. (2020); Chen et al. (2018); Hackius and Petersen } \\
\text { (2017); Sultan and Lakhani (2018); Swan (2015); Tapscott and } \\
\text { Tapscott (2016); Zheng et al. (2017) }\end{array}$ \\
\hline Decentralised & $\begin{array}{l}\text { Blockchain is a decentralized managing } \\
\text { technique of Bitcoin. There is no central } \\
\text { storage. This may minimise the disruption risks. } \\
\text { It supports a decentralized decision-making. }\end{array}$ & $\begin{array}{l}\text { Astarita et al. (2020); Chen et al. (2018); Dobrovnik et al. (2018); } \\
\text { Hackius and Petersen (2017); Mansfield-Devine (2017); Pereira } \\
\text { et al. (2019); Swan (2015); Tapscott and Tapscott (2016); Yli- } \\
\text { Huumo et al. (2016); Zyskind et al. (2015) }\end{array}$ \\
\hline Trust & $\begin{array}{l}\text { The trust is different from conventional trust. } \\
\text { Blockchain creates trustless network by using } \\
\text { sophisticated math. Business partners can } \\
\text { trade together without knowing each other. }\end{array}$ & $\begin{array}{l}\text { Batwa and Norrman (2020); Beck et al. (2016); Chen et al. } \\
\text { (2018); Christidis and Devetsikiotis (2016); Dobrovnik et al. } \\
\text { (2018); Kosba et al. (2016); Mansfield-Devine (2017); Sultan and } \\
\text { Lakhani (2018); Tapscott and Tapscott (2016); Underwood } \\
\text { (2016) }\end{array}$ \\
\hline Transparency and visibility & $\begin{array}{l}\text { The data is almost simultaneously validated } \\
\text { and broadcasted to all nodes in blockchains. } \\
\text { The transactions or records cannot be hidden } \\
\text { so this creates more trust and adds value to the } \\
\text { business system. }\end{array}$ & $\begin{array}{l}\text { Caro et al. (2018); Dobrovnik et al. (2018); Jawaji et al. (2020); } \\
\text { Sultan and Lakhani (2018); Tapscott and Tapscott (2016); } \\
\text { Underwood (2016); Yang et al. (2019); Zyskind et al. (2015) }\end{array}$ \\
\hline Security & $\begin{array}{l}\text { Advanced computational logic, cryptographic } \\
\text { technology and a distributed decentralized } \\
\text { network offer a secure environment. Moreover, } \\
\text { it provides not only confidentiality, but also } \\
\text { authenticity and nonrepudiation to all activity. }\end{array}$ & $\begin{array}{l}\text { Caro et al. (2018); Jawaji et al. (2020); Kosba et al. (2016); } \\
\text { Mansfield-Devine (2017); Tapscott and Tapscott (2016); } \\
\text { Underwood (2016); Yang et al. (2019); Yli-Huumo et al. (2016) }\end{array}$ \\
\hline Global Network & $\begin{array}{l}\text { Blockchain technologies rely on shared } \\
\text { information. It can be extended globally. It is a } \\
\text { standardised global network. }\end{array}$ & $\begin{array}{l}\text { Sultan and Lakhani (2018); Swan (2017); Tapscott and Tapscott } \\
\text { (2016); Underwood (2016) }\end{array}$ \\
\hline
\end{tabular}

\subsubsection{Immutable}

In a blockchain, all the transactions or records are sorted by hashing function into series of blocks, and each block is chained. Hashing and cryptography are used to create data stored in blockchain which is almost immutable due to the tremendous amount of computing power that would be required to manipulate the original state of the block. This does not only allow different parties in the networks to transfer value or assets, but also creates a trustless network by using sophisticated math (Christidis and Devetsikiotis, 2016; Tapscott and Tapscott, 2016). Although immutable may be considered as a dimension of security, this unique attribute can have important practical implications in the business world, for example, improving the traceability in supply chain and logistic operations (Alkhodre et al., 2019; Astarita et al., 2020). Thus, this paper considers the immutability as one of the important attributes of a blockchain. 


\subsubsection{Trust}

Blockchain provides a new trust mechanism, which relies on cryptographic technology and a distributed decentralized network (Tapscott and Tapscott, 2016). Moreover, blockchain does not require trust in a third party (Zyskind et al., 2015). A good relationship based on mutual trust plays a vital role for supply chain (Chen et al., 2010; Luo et al., 2012; Mirkovski et al., 2012). Blockchain system is running without trust concerns, making a transaction "trust free" (Beck et al., 2016). This important attribute of blockchain enables different business partners to work together without the conventional trust (Kosba et al., 2016; Mansfield-Devine, 2017). In addition, a blockchain network facilities the information sharing among the supply chain partners. The trustless network definitely enhances the relationships among different supply chain partners (Soosay and Hyland, 2015).

\subsubsection{Decentralisation}

A blockchain is a peer-to-peer network (Swan, 2017; Tschorsch and Scheuermann, 2016; Underwood, 2016). It changes the way to store and share data. Each member keeps their own copy of ledger in a blockchain network. In a decentralized system, data is no longer stored in a centralized database, and the data is immutable and transparent to all members in a blockchain. There is no third party to validate a block of transactions. In a supply chain system, the decentralized blockchain network promotes visibility among the supply chain partners who can access the information without permission (Tapscott and Tapscott, 2016). The blockchain technology enables a digital transition from centrally controlled platforms to decentralised platform control in the era of Industry 4.0 (Wang et al., 2020). It also supports distributed manufacturing and decentralized decision-making, which provide more flexible environment to all users. For example, in the automotive manufacturing industry, the manufacturer's suppliers could change the delivery schedule due to unexpected issues. Fortunately, all other businesses across the supply chain will receive this update immediately; hence supply chain partners may make their own decisions frequently and effectively. Decentralization also adds more security as the data stored on one node must be validated and broadcasted to all nodes in the network. In other words, other nodes can back up and prevent a disruption in the event of a node failure. This is an important attribute to prevent a supply chain disruption due to a centralised information network failure.

\subsubsection{Transparency and Visibility}

Transparency and visibility is another important attribute of blockchain (Frank et al., 2019). Because blockchain is a highly decentralised network, which is different from traditional centralised database, all the different users can almost simultaneously receive update information in the network. In supply chains, many business problems / uncertainty can be solved by sharing real-time information (Wang, 2018). During supply chain process, if components modification is to be updated in the system, and all businesses to be notified, blockchain could effectively update all relevant users and stakeholder at the same time. For instance, a production ID replacement will introduce a significant impact on the whole process, hence delivery company, manufactory and stock management department should be aware of this change immediately (Wang et al., 2018). Another example is related to the sharing of the customers' demand information through the entire supply chain network. Such an approach may significantly reduce the inventory costs, but it is difficult to keep all supply chain business partners synchronised in a conventional network. Blockchain technology, in this case, facilitates the transparency and visibility in a network.

\subsubsection{Security}

Security is a multidimensional concept in a blockchain. Swan (2017) argues that cybersecurity is one of the biggest drivers of blockchain adoption. In this paper, security refers to the following aspects. Firstly, blockchain provides a mechanism to allow all nodes to validate and store the data without a third party. Secondly, the data stored on blockchains is almost immutable, in other words, it is almost impossible to modify, delete or change information or blocks without being detected by other users. Thirdly, it is almost impossible to hack a blockchain, as mentioned before, a decentralised network can retrieve and validate the information through the network (Swan, 2015; Yli-Huumo et al., 2016).

\subsubsection{Global Network}

The blockchain is still in its infancy (Swan, 2015). However, it has already demonstrated a huge potential for future development. With the development of information technology, blockchain network can quickly grow up in different areas beyond bitcoin. Marsal-Llacuna (2018) considers blockchain as a connecting mechanism to connect data processing technologies. The attributes of blockchain can be implemented in different contexts. The blockchain network is based on a peer-to-peer network, as a result, businesses may no longer need a third party / intermediary to sell the products and/or services. Blockchains are smart networks (Frank et al., 2019; Swan, 2017), which can interact with different technologies e.g. smart contracts, Artificial Intelligence (AI), internet of things (IoT), 3-D printing, etc. to totally change the traditional seller-buyer relationship globally (Hackius and Petersen, 2017; Kosba et al., 2016; Swan, 2015; Yli-Huumo et al., 2016). Moreover, Sultan and Lakhani (2018) argue that blockchain is a marketplace. It may be considered as a disruptive innovation later.

Zheng et al. (2018) argue that blockchain can be applied into diverse applications far beyond cryptocurrencies, particularly in the next generation of internet interaction systems. Mansfield-Devine (2017) asserts that blockchain provides a kind of chain of trust in the commercial world. So far, most studies focus on the utilization of blockchain to facilitate the information flow and financial flow (Tschorsch and Scheuermann, 2016; YliHuumo et al., 2016; Zheng et al., 2017). Yli-Huumo et al. (2016) find that security is a major research topic in recent blockchain studies, and over $80 \%$ blockchain studies focus on Bitcoin in terms of a systematic review. We consider the use of blockchain for supply chain collaboration and integration because it provides a conceptual idea to collaborate different nodes/parties/people, and integrates 
finance, information, and goods flows and technologies in a supply chain.

\subsection{Practical Uses}

In this section, the practical uses of blockchain are demonstrated in supply chain management. A supply chain can be simply understood as three phases including source, make, and deliver (Lambert et al., 1998). However, a supply chain is a complex system. There are many factors, which would influence the blockchain applications in businesses, need to be carefully considered. Furthermore, each industry may have different focuses or priorities. For example, the food industry may require a high level of quality and food safety standards through entire supply chain. The forest industry may focus on improving efficiency of processes for manufacturing and reducing the cost of transport. Pharmaceutical industry may focus on the improvement of product innovation and R\&D for source and make (Wang and Jie, 2019). Therefore, it is meaningful to assess the use of blockchain in terms of the specific requirements in a particular business field.

As the informal interview was conducted to verify and support the findings in New Zealand, we did not focus on the specific industry in the interview. Having said that, we focused on three important practical implications: information sharing, traceability and automation in digital transformation (Chang and Chen, 2020; Frank et al., 2019; Wollschlaeger et al., 2017), which were confirmed in the informal interview, and seemed to be popular for blockchain applications. Our Monash University IT research group adopted three international cases to demonstrate that the use of blockchain in supply chain collaboration and integration.

\subsubsection{Information Sharing (IBM Maersk)}

In traditional supply chain processes, especially international business, there are large number of communications and documents, which require lots of efforts and time to complete. These include legal documents and contracts which companies will incur costs to provide and transfer. Blockchain could provide a solution as each document or paper can be uploaded and shared to individual department or business, hence significantly reducing the efforts for communications or transferring papers and improving the information sharing in a supply chain (Benton et al., 2018; Wollschlaeger et al., 2017).

For instance, IBM and Maersk developed a shipping blockchain called TradeLens, which is a platform draws a sample process of international supply chain. During the process, all transfer processes will share live status to every user, therefore everyone will immediately acknowledge the latest information. Consequently, blockchain technology will integrate the supply chain network and assist business reducing cost and improving supply chain collaboration and information sharing. It has enormous potential to spur the industry to digitize the supply chain and build collaboration around common standards.

\subsubsection{Traceability (Carrefour)}

Traceability is also known as auditability or scrutiny. The technology can be used to provide identification and trace the raw materials and final products in supply chains
(Angeles, 2009). Due to the design of blockchain, all users can easily trace the block in the network. In addition, the real-time data add value to business operations. The blockchain comprises series of block (Swan, 2015; Tapscott and Tapscott, 2016). Transactions or records are stored respectively in different blocks and linked by the cryptographic hash function. This would provide an important feature to trace the blocks. In a supply chain system, business partners can use the feature of blockchain to trace and monitor blocks in the network. The block may contain key information, products, process history, shipments, ingredients, etc. It enables information sharing, which improves the visibility and transparency of supply chains. Furthermore, the business partners may quickly access information without permissions (Apte and Petrovsky, 2016; Hackius and Petersen, 2017; Swan, 2017). In a manufacturing system, the material information can be uploaded into blockchains with specific ID and description, therefore, other supply chain partners and customers could immediately and correctly find out details of that material.

In March 2019, Carrefour used blockchain technology to enhance the traceability in its milk supply chain. Carrefour is a French retail giant, which operates 12,300 retail shops and supermarkets in more than 30 countries in Europe, the Americas, Asia and Africa. The blockchain allows information to be securely exchanged between producers, suppliers and customers across the supply chain. Customers and business partners can scan the QR code on Carrefour Quality Line milk bottles to identify the various stakeholders involved in the milk supply chain and conduct quality checks. This improves the supply chain integration and collaboration by adding trust and a long-term commitment in a supply chain (Soosay and Hyland, 2015).

\subsubsection{Automation in Digital Transformation (Chainlink)}

The automation in digital transformation is an important practical feature of blockchain (Christidis and Devetsikiotis, 2016; Frank et al., 2019), it can be widely adopted in supply chains. Blockchain alone cannot achieve automation in business. However, it provides a new decentralised paradigm for supply chain integration and collaboration including people, finance, information, goods and technologies (Tapscott and Tapscott, 2016). Blockchain can improve the efficiency through automatic data processing and eliminate the intermediaries (Chen et al., 2018; Dobrovnik et al., 2018), and robots and autonomous guided vehicles (Frank et al., 2019; Gilchrist, 2016). In addition, it may be used in conjunction with other technologies to enable a smart supply chain in industries. Sultan and Lakhani (2018) and Mougayar (2016) argue for blockchain as a development platform. The smart supply chain network may be built on a blockchain network and it comprises a series of IoT devices, $5 \mathrm{G}$, smart contracts, and various kinds of AI technologies (e.g. robotics, machine learning, vision, planning, scheduling \& optimization, expert systems, etc.) to achieve complete autonomy in business (Christidis and Devetsikiotis, 2016; Gilchrist, 2016).

A smart contract can organize the supply chain related information in the local data structure to allow content-based search and enable efficient information retrieval. In addition, it can easily detect duplicated transactions and remove it immediately. Meanwhile, update products' status will be 
much more effective via blockchain smart contract structure (Su et al., 2018). Furthermore, smart contract and smart supply create low query response time and higher accuracy environment. For example, Chainlink, which is an integrated company, applied automation transfer process with cryptotokens technology. Therefore, any transactions will be unstoppable and validated during supply chain process. Apparently, smart contract could assist supply chain to easily process each transaction and validate all data flow. By using this technology, Chainlink will help business reduces above $80 \%$ error transformation and cut off $30 \%$ time among the entire business. In other words, blockchain technology will assist businesses effectively integrate the internal and external processes.

\section{DISCUSSION}

Blockchain is one of the emerging technologies in the Industry 4.0 era (Frank et al., 2019; Gilchrist, 2016; Tapscott and Tapscott, 2016). It provides an idea to store, verify and share transaction data among different nodes. This technology may help companies to build a trustless network (Christidis and Devetsikiotis, 2016) and optimise the goods, information and financial flows in a supply chain. This technology may change our business world disruptively (Swan, 2015; Tapscott and Tapscott, 2016). However, blockchain alone will not make any disruptive changes. According to STT, it is a technology whose values need to be utilised and demonstrated in particular business contexts. This study focuses on the blockchain technology and supply chain collaboration and integration.

Supply chain integration and collaboration has become an important trend in supply chain management (Chen et al., 2017; Ramanathan and Gunasekaran, 2014; Soosay and Hyland, 2015). A truly integrated and collaborative supply chain does more than reduce costs. It also creates value for the customers, manufacturers, supply chain partners, and its shareholders (Chen et al., 2017; Lee, 2000; Lee and Rha, 2016; Maiga, 2016). Supply chain integration and collaboration have been identified as a key practice to achieve effectiveness and efficiency (Chen et al., 2017; Flynn et al., 2010; Wiengarten et al., 2016). It can provide a company with the opportunity to concentrate its core business and compete in an international market (SimchiLevi et al., 2007; Wang et al., 2015). In addition, effective management of a supply chain has been increasingly recognised as a key factor in differentiating product and service offerings and gaining competitive advantage and sustainability for firms (Chen et al., 2017; Das and Mitra, 2018). In this paper, we find that the blockchain technology may promote supply chain integration and collaboration by facilitating information sharing, traceability and automation in digital transformation.

There are common characteristics between blockchain and supply chain networks. Firstly, both the blockchain and supply chain are a network structure, they comprise different users, nodes, internal and/or external stakeholders. Secondly, the blockchain is a decentralised network, and most business partners/ companies usually make decentralized decisions in a conventional supply chain. Thirdly, both blockchain and supply chain networks heavily rely on the connections or relationships among the nodes and partners. Fourthly, both blockchain and supply chain require a certain level of collaboration and integration.

In addition, according to the RBV, a firm's resources are made up of different skills, capabilities, financial resources, and human and physical resources including technology. These are coordinated and deployed to generate competitive advantage (Mohamed et al., 2014). The blockchain technology strengthens the capabilities of supply chain integration and collaboration through the key attributes of a blockchain, such as immutable, trust, decentralised, transparency and visibility (Benton et al., 2018), and generate competitive advantage for companies. Overall, the authors argue that the blockchain technology provides a new decentralised paradigm for integration and collaboration including people, finance, information, goods and technologies in supply chains.

As discussed previously, the development of blockchain is still emerging. Further, other technologies including robotic technology, 5G, AI, IoT, 3-D printing and big data can be used in conjunction with blockchain technology in the Industry 4.0 era (Christidis and Devetsikiotis, 2016; Frank et al., 2019; Gilchrist, 2016). For example, IoT systems can assist blockchain enhancing traceability by connecting sensors, providing consumers and retailers are willing to trace the entire process of supply chain. Other applications include monitoring delivery process, machine learning model of arranging available resource and predicting potential risks, and tracing the origin of raw material. With the installation of different types of sensors, IoT systems can generate various of traceability reports by extracting diverse real-time data and integrates them (Gilchrist, 2016). Manufacturers can effectively arrange the logistic resources bases on IoT system's availability reports, therefore a client can easily find out the delivery status and time-line. Furthermore, after sharing the live information, blockchain will be able to store certain important data from IoT. Global businesses' operational and economical risk can be significantly managed (Tapscott and Tapscott, 2016), because blockchain and IoT's traceability function would help all stakeholders understand supply chain processes timely. Blockchain stores all trading contracts and summary of transactions, therefore helps business to measure potential financial risk accurately.

There may be more important features to come. So far, this paper argues that traceability is one of the important practical features of blockchain in supply chains. The traceability can be widely used for different business purposes, e.g., the quality control, reverse logistics, counterfeit, service monitoring, regulations, etc. The blocks may be used to record certain information, e.g., quantity, conditions, location, time, etc. from different stakeholders, i.e., supplier, manufacturer, etc. to help relevant supply chain partners to trace back to origin. This is a very useful feature for most industries, e.g., food industry can use the traceability to comply the food safety standards, and government regulations (National Animal Identification and Tracing Act 2012). Forest industry can use the traceability to plan and control different grades of timber from different places to improve the efficiency and productivity. It also can be used for anti-counterfeit (Apte and Petrovsky, 2016; Caro et al., 2018; Dobrovnik et al., 2018). Moreover, the traceability adds more intangible values along supply chains. 


\subsection{Potential Challenges}

Most previous studies have discussed the challenges or potential issues of blockchain technology from a technical perspective, such as complexity, scalability, privacy problem, security, selfish mining, further applications (Bai and Sarkis, 2020; Christidis and Devetsikiotis, 2016; Swan, 2017). During the study, we found the following potential challenges of implementing a blockchain in supply chains in New Zealand.

Regulatory issue is a major question in New Zealand. Typically, a conventional database is managed by a third party. However, a decentralised network does not have a third party who is in control of the transactions and data. YliHuumo et al. (2016) argue that data integrity is an essential issue in the blockchain environment. This may imply an important question in a supply chain. How can business partners ensure that the data are accurate from different nodes? The authors suggest that there are two ideas. Firstly, the blockchain can be linked directly with IoT and a smart contract to ensure data integrity (Christidis and Devetsikiotis, 2016). Secondly, lack of regulation may cause many other potential issues; hence governments should work with stakeholders to improve relevant data regulations in industries.

The additional cost or risk for implementing in-house blockchain technology is another important question for business management. There have been arguments between the costs and benefits for applying blockchain in companies. Blockchain is different from other equipment or machine, it is not only the company who needs to spend on infrastructure and training, but also (and more importantly) all the relevant business parties need to embrace the complicated changes e.g., new business models, new procedure, innovation, collaborations, etc. In fact, blockchain may simplify and automate the business transactions (Dobrovnik et al., 2018; Swan, 2017) e.g., reduce time, minimise risk, etc. in a complex supply chain. No risk, no reward. The authors suggest that companies who are interested in blockchain should carefully conduct their research and achieve a clear vision of blockchain applications from all relevant business stakeholders, before investing heavily in blockchain and/or relevant technologies.

\section{CONCLUSIONS}

In this paper, we firstly provided an overview of the blockchain, and identified and explained the important attributes of blockchains. We then took a closer look at the practical uses of blockchain in supply chains. A supply chain system normally contains a group of companies, and different types of flow including information, finance and goods. It is crucial to collaborate with business partners and integrate the flows to improve overall performance and create competitive advantages for companies. In the literature, blockchain has many powerful features which can be widely used in different fields. This paper argued that blockchain may facilitate supply chain collaboration and integration. Further, applications of blockchain including information sharing, traceability and automation can enable supply chain collaboration and integration, and a couple of potential questions of blockchain regarding supply chain are discussed in the paper.
Blockchain is a relatively new technology. Not many companies are using the blockchain in New Zealand yet, and there have been questions around implementing blockchain. The following limitations of the study are identified: firstly, a small number of companies have been studied in New Zealand, this may be difficult to generalise the results. Secondly, the study is exploratory, the results illustrate that blockchain enables the supply chain collaboration and integration, but this study did not discuss in depth in specific industry or problems. Thus, it is significant to conduct further blockchain researches in certain industries and explore more advantages and implications of the blockchain, which can be applied in the business operations based on STT. This would contribute to the further development of technology in the industry 4.0 era (Wang et al., 2020).

Blockchain alone will not make disruptive changes in the business world. However, this provides directions / ideas for future research. Two main directions of research are suggested. The first is identifying the business needs, which are defined at a high level may include capability needs (statements about providing services, delivering products, assisting others in need, or ensuring the business's own operational effectiveness) or improvement needs (suggestions meant to increase efficiencies or reducing costs, effort, or time-to-market). The second is for technology exploration research with the ultimate goal being to develop innovative services based on new information and communication technologies. The traditional service development is normally triggered by the consumers' requirements to create new services. However, the new technology exploration starts from new available technologies.

Last but not least, we suggest that it is important to combine blockchain with other new technologies such as IoT, smart contract, AI, 3D printing, 5G, big data communication platform, etc. and invite the end users / companies to provide ideas for innovative services. Both further researches may need to focus on the particular industry or company and analyse the relevant barriers and/or business constraints / problems, then to explore, develop and apply relevant technologies and/or new strategies to optimise and resolve the business problems by adding social perspective in STT. This study would help government, managers and researchers to have a better understanding of the utilization of the blockchain in business, particularly in supply chain management. It contributes to the blockchain and supply chain management literature. This would provide a foundation for further blockchain researches.

\section{ACKNOWLEDGEMENTS}

This work is performed under the support of Scion (New Zealand Forest Research Institute), which is a Crown Research Institute focused on improving the international competitiveness of the New Zealand forestry industry and building a stronger bio-based economy.

\section{REFERENCES}

Alfalla-Luque, R., Marin-Garcia, J., \& Medina-Lopez, C. (2015). An analysis of the direct and mediated effects of employee commitment and supply chain integration 
on organisational performance. International Journal of Production Economics, 162, 242.

Alkhodre, A., Ali, T., Jan, S., Alsaawy, Y., Khusro, S., \& Yasar, M. (2019). A Blockchain-based value added tax (VAT) system: Saudi Arabia as a use-case. International Journal of Advanced Computer Science and Applications, 10(5), 708-716.

Angeles, R. (2009). Anticipated IT infrastructure and supply chain integration capabilities for RFID and their associated deployment outcomes. International Journal of Information Management, 29(3), 219-231. https://doi.org/https://doi.org/10.1016/j.ijinfomgt.2008 .09 .001

Apte, S., \& Petrovsky, N. (2016). Will blockchain technology revolutionize excipient supply chain management? Journal of Excipients and Food Chemicals, 7(3), 76-78.

Astarita, V., Giofrè, V. P., Mirabelli, G., \& Solina, V. (2020). A Review of Blockchain-Based Systems in Transportation. Information (Switzerland), 11(1). https://doi.org/10.3390/info11010021

Bai, C., \& Sarkis, J. (2020). A supply chain transparency and sustainability technology appraisal model for blockchain technology. International Journal of Production Research. https://doi.org/10.1080/00207543.2019.1708989

Batwa, A., \& Norrman, A. (2020). A Framework for Exploring Blockchain Technology in Supply Chain Management. Operations and Supply Chain Management: An International Journal 13(3), 294306. https://doi.org/10.31387/oscm0420271

Beck, R., Stenum Czepluch, J., Lollike, N., \& Malone, S. (2016). Blockchain-the gateway to trust-free cryptographic transactionsSpringer. Symposium conducted at the meeting of the European Conference on Information Systems, İstanbul,Turkey.

Benton, M., Radziwill, N., Purritano, A., \& Gerhart, C. (2018). Blockchain for Supply Chain: Improving Transparency and Efficiency Simultaneously. Software Quality Professional, 20(3), 28-38.

Bezuidenhout, C. (2017). Eliciting and re-distributing information along the forestry value chain to promote more efficient and fair supply chain behaviour Symposium conducted at the meeting of the 15th ANZAM Operations, Supply Chain and Services Management Symposium Queenstown, New Zealand.

Bostrom, R. P., \& Heinen, J. S. (1977). MIS Problems and Failures: A Socio-Technical Perspective. Part I: The Causes. MIS Quarterly, 1(3), 17-32. https://doi.org/10.2307/248710

Bryman, A. (2012). Social research methods (4th ed. ed.). Oxford: Oxford University Press.

Caro, M. P., Ali, M. S., Vecchio, M., \& Giaffreda, R. (2018). Blockchain-based traceability in Agri-Food supply chain management: A practical implementationInstitute of Electrical and Electronics Engineers Inc. Symposium conducted at the meeting of the 2018 IoT Vertical and Topical Summit on Agriculture - Tuscany, IOT Tuscany 2018 Retrieved from

https://www.scopus.com/inward/record.uri?eid=2s2.0-85049345489\&doi=10.1109\%2fIOT-
TUSCANY.2018.8373021 \&partnerID=40\&md5=655 ed03963f912ec351ea4e888d9bfc3

https://ieeexplore.ieee.org/document/8373021/ https://doi.org/10.1109/IOTTUSCANY.2018.8373021

Cartelli, A. (2007). Socio-Technical Theory and Knowledge Construction: Towards New Pedagogical Paradigms? Issues in Informing Science \& Information Technology, 4, 1-14. https://doi.org/10.28945/928

Chang, S. E., \& Chen, Y. (2020). When blockchain meets supply chain: A systematic literature review on current development and potential applications. IEEE Access, 8 , 62478-62494.

https://doi.org/10.1109/ACCESS.2020.2983601

Chen, G., Xu, B., Lu, M., \& Chen, N.-S. (2018). Exploring blockchain technology and its potential applications for education. Smart Learning Environments, 5(1), 1-10. https://doi.org/10.1186/s40561-017-0050-X

Chen, H., Tian, Y., Ellinger, A., \& Daugherty, P. (2010). Managing logistics outsourcing relationships: An empirical investigation in China. Journal of Business Logistics, 31(2), 279-XIII. https://doi.org/10.1002/j.2158-1592.2010.tb00152.x

Chen, L., Zhao, X., Tang, O., Price, L., Zhang, S., \& Zhu, W. (2017). Supply chain collaboration for sustainability: A literature review and future research agenda. International Journal of Production Economics, 194, 73-87. https://doi.org/https://doi.org/10.1016/j.ijpe.2017.04.0 05

Christidis, K., \& Devetsikiotis, M. (2016). Blockchains and Smart Contracts for the Internet of Things. IEEE Access, 4, 2292-2303. https://doi.org/10.1109/ACCESS.2016.2566339

Christopher, M. (2005). Logistics and supply chain management : strategies for reducing costs, improving services and managing the chain of demand (3rd ed. ed.). New York: New York : Financial Times Prentice Hall.

Christopher, M., \& Peck, H. (2012). Marketing Logistics (2nd ed. ed.). Hoboken: Taylor and Francis.

Cole, R., Stevenson, M., \& Aitken, J. (2019). Blockchain technology: implications for operations and supply chain management. Supply Chain Management, 24(4), 469-483. https://doi.org/10.1108/SCM-09-2018-0309

Conte de Leon, D., Stalick, A. Q., Jillepalli, A. A., Haney, M. A., \& Sheldon, F. T. (2017). Blockchain: properties and misconceptions. Asia Pacific Journal of Innovation and Entrepreneurship, 11(3), 286-300. https://doi.org/doi:10.1108/APJIE-12-2017-034

Das, K., \& Mitra, A. (2018). Integrating Sustainability in the Design and Planning of Supply Chains. Operations and Supply Chain Management: An International Journal 11(4), 161-185. https://doi.org/10.31387/oscm0350212

Dobrovnik, M., Herold, D., Fürst, E., \& Kummer, S. (2018). Blockchain for and in Logistics: What to Adopt and Where to Start. Logistics, 2(3). https://doi.org/10.3390/logistics2030018

Flynn, B., Huo, B., \& Zhao, X. (2010). The impact of supply chain integration on performance: A contingency and configuration approach. Journal of Operations 
Management, $28(1)$ https://doi.org/10.1016/j.jom.2009.06.001

Frank, A. G., Dalenogare, L. S., \& Ayala, N. F. (2019). Industry 4.0 technologies: Implementation patterns in manufacturing companies. International Journal of Production Economics, 210, 15-26. https://doi.org/https://doi.org/10.1016/j.ijpe.2019.01.0 04

Garrod, J. Z. (2016). The Real World of the Decentralized Autonomous Society. tripleC: Communication, Capitalism \& Critique, 14(1), 62-77. https://doi.org/10.31269/triplec.v14i1.692

Gilchrist, A. (2016). Industry 4.0: The Industrial Internet of Things. Berkeley, CA: Berkeley, CA: Apress. https://doi.org/10.1007/978-1-4842-2047-4

Hackius, N., \& Petersen, M. (2017). Blockchain in logistics and supply chain : trick or treat?epubli. Symposium conducted at the meeting of the Proceedings of the Hamburg International Conference of Logistics (HICL) Hamburg, Germany.

Hafeez, K., Zhang, Y., \& Malak, N. (2002). Determining key capabilities of a firm using analytic hierarchy process. International Journal of Production Economics, 76(1), 39-51. https://doi.org/10.1016/S0925-5273(01)001414

Huddiniah, E. R., \& Er, M. (2019). Product Variety, Supply Chain Complexity and the Needs for Information Technology: A Framework Based on Literature Review. Operations and Supply Chain Management: An International Journal 12(4), 245-255. https://doi.org/10.31387/oscm0390247

Jawaji, O., Asnani, B., Balasubramanian, S., \& Poovammal, E. (2020). Tracing products in a supply chain using blockchain. International Journal of Advanced Science and Technology, 29(6), 2186-2200.

Kim, S. W. (2006). Effects of supply chain management practices, integration and competition capability on performance. Supply Chain Management: An International Journal, 11(3), 241-248. https://doi.org/10.1108/13598540610662149

Kosba, A., Miller, A., Shi, E., Wen, Z., \& Papamanthou, C. (2016). Hawk: The Blockchain Model of Cryptography and Privacy-Preserving Smart Contracts Symposium conducted at the meeting of the IEEE Symposium on Security and Privacy (SP), San Jose, CA, USA.

Lai, K.-H., Ngai, E. W. T., \& Cheng, T. C. E. (2004). An empirical study of supply chain performance in transport logistics. International Journal of Production Economics, $\quad$ 87(3), 321-331. https://doi.org/10.1016/j.ijpe.2003.08.002

Lambert, M. D., Cooper, C. M., \& Pagh, D. J. (1998). Supply Chain Management: Implementation Issues and Research Opportunities. The International Journal of Logistics Management, 9(2), 1-20. https://doi.org/10.1108/09574099810805807

Lee, H. L. (2000). Creating value through Supply Chain integration Supply Chain Management Review, 4(4), 30.

Lee, S., \& Rha, J. S. (2016). Ambidextrous supply chain as a dynamic capability: building a resilient supply chain. Management Decision, 54(1), 2-23. https://doi.org/10.1108/MD-12-2014-0674
Liao, S.-H., Hu, D.-C., \& Ding, L.-W. (2017). Assessing the influence of supply chain collaboration value innovation, supply chain capability and competitive advantage in Taiwan's networking communication industry. International Journal of Production Economics, 191, 143-153. https://doi.org/https://doi.org/10.1016/j.ijpe.2017.06.0 01

Luo, Y., Huang, Y., \& Wang, S. (2012). Guanxi and Organizational Performance: A Meta-Analysis. Management and Organization Review, 8(1), 139. https://doi.org/10.1111/j.1740-8784.2011.00273.x

Maiga, A. (2016). Assessing the Impact of Supply Chain Integration on Firm Competitive Capability. International Journal of Operations Research and Information Systems (IJORIS), 7(1), 1-21. https://doi.org/10.4018/IJORIS.2016010101

Mansfield-Devine, S. (2017). Beyond Bitcoin: using blockchain technology to provide assurance in the commercial world. Computer Fraud \& Security, 2017(5),

14-18.

https://doi.org/https://doi.org/10.1016/S13613723(17)30042-8

Marsal-Llacuna, M.-L. (2018). Future living framework: Is blockchain the next enabling network? Technological Forecasting and Social Change, 128, 226-234. https://doi.org/https://doi.org/10.1016/j.techfore.2017. 12.005

Mirkovski, K., Davison, R., \& Schneider, C. (2012). Emergence and development of inter-organizational relationships in international supply chains: The Macedonian winery case Symposium conducted at the meeting of the 18th Americas Conference on Information Systems 2012, AMCIS 2012, Seattle, WA. Retrieved from https://www.scopus.com/inward/record.uri?eid=2s2.0-

84877879494\&partnerID=40\&md5=adb87b7ece237e 281ad82168a9c9ad58

Mohamed, Z. A., Ann, H. J., \& Yee, W. F. (2014). Strategic Management. Selangor Darul Ehsan, Malaysia: Oxford University Press.

Mougayar, W. a. (2016). The business blockchain : promise, practice, and application of the next Internet technology: Hoboken, New Jersey : John Wiley \& Sons, Inc.

Pereira, J., Tavalaei, M. M., \& Ozalp, H. (2019). Blockchainbased platforms: Decentralized infrastructures and its boundary conditions. Technological Forecasting and Social Change, 146, 94-102. https://doi.org/https://doi.org/10.1016/j.techfore.2019. 04.030

Porter, M. G. (2019). Supply Chain Integration: Does Organizational Culture Matter? Operations and Supply Chain Management: An International Journal 12(1), 49-59. https://doi.org/10.31387/oscm0360222

Pradabwong, J., Braziotis, C., Tannock, J. D. T., \& Pawar, K. S. (2017). Business process management and supply chain collaboration: effects on performance and competitiveness. Supply Chain Management: An International Journal, 22(2), 107-121. https://doi.org/10.1108/SCM-01-2017-0008 
Ramanathan, U., \& Gunasekaran, A. (2014). Supply chain collaboration: Impact of success in long-term partnerships. International Journal of Production Economics, 147, 252-259. https://doi.org/https://doi.org/10.1016/j.ijpe.2012.06.0 02

Simchi-Levi, D., Kaminsky, P., \& Simchi-Levi, E. (2007). Designing and managing the supply chain : concepts, strategies, and case studies (3 ed.). Boston: McGrawHill/Irwin

Soosay, C. A., \& Hyland, P. (2015). A decade of supply chain collaboration and directions for future research. Supply Chain Management: An International Journal, 20(6), 613-630. https://doi.org/10.1108/SCM-06-20150217

Su, S., Wang, K., \& Kim, H. S. (2018). Smartsupply: Smart Contract Based Validation for Supply Chain Blockchain (pp. 988-993).

Sultan, K., \& Lakhani, R. (2018). Conceptualizing Blockchains: Characteristics \& Applications. arXiv.org.

Swan, M. (2015). Blockchain: BLUEPRINT FOR A NEW ECONOMY. Sebastopol, CA: O'Reilly Media, Inc.

Swan, M. (2017). Anticipating the Economic Benefits of Blockchain. Technology Innovation Management Review, $7(10)$, 6-13. https://doi.org/10.22215/timreview/1109

Tapscott, D., \& Tapscott, A. (2016). Blockchain revolution : how the technology behind bitcoin is changing money, business, and the world: New York : Portfolio / Penguin.

Tschorsch, F., \& Scheuermann, B. (2016). Bitcoin and Beyond: A Technical Survey on Decentralized Digital Currencies. Communications Surveys \& Tutorials, IEEE, 18(3), 2084-2123. https://doi.org/10.1109/COMST.2016.2535718

Tsou, C.-M. (2013). On the strategy of supply chain collaboration based on dynamic inventory target level management: A theory of constraint perspective. Applied Mathematical Modelling, 37(7), 5204-5214. https://doi.org/https://doi.org/10.1016/j.apm.2012.10.0 31

Underwood, S. (2016). Blockchain Beyond Bitcoin. Association for Computing Machinery. Communications of the ACM, 59(11), 15. https://doi.org/10.1145/2994581

Wang, M. (2018). Impacts of supply chain uncertainty and risk on the logistics performance. Asia Pacific Journal of Marketing and Logistics, 30(3), 689-704. https://doi.org/10.1108/APJML-04-2017-0065

Wang, M., Asian, S., Wood Lincoln, C., \& Wang, B. (2020). Logistics innovation capability and its impacts on the supply chain risks in the Industry 4.0 era. Modern Supply Chain Research and Applications, 2(1), 1-16. https://doi.org/10.1108/mscra-07-2019-0015

Wang, M., \& Jie, F. (2019). Managing supply chain uncertainty and risk in the pharmaceutical industry. Health Services Management Research, 0951484819845305. https://doi.org/10.1177/0951484819845305
Wang, M., Jie, F., \& Abareshi, A. (2015). A conceptual framework for mitigating supply chain uncertainties and risks in the courier industry. International Journal of Supply Chain and Operations Resilience, 1(4), 319. 338. https://doi.org/10.1504/IJSCOR.2015.075083

Wang, M., Jie, F., \& Abareshi, A. (2015). Evaluating logistics capability for mitigation of supply chain uncertainty and risk in the Australian courier firms. Asia Pacific Journal of Marketing and Logistics, 27(3), 486-498. https://doi.org/doi:10.1108/APJML-11-20140157

Wang, M., Jie, F., \& Abareshi, A. (2018). Improving logistics performance for one belt one road: a conceptual framework for supply chain risk management in Chinese third-party logistics providers. International Journal of Agile Systems and Management, 11(4), 364-380. https://doi.org/10.1504/ijasm.2018.095515

Wang, M., Jie, F., \& Abareshi, A. (2018). Logistics Capability, Supply Chain Uncertainty and Risk, and Logistics Performance: An Empirical Analysis of Australian Courier Industry. Operations and Supply Chain Management: An International Journal, 11(1), 45-54.

Wiengarten, F., Humphreys, P., Gimenez, C., \& McIvor, R. (2016). Risk, risk management practices, and the success of supply chain integration. International Journal of Production Economics, 171, 361-370. https://doi.org/https://doi.org/10.1016/j.ijpe.2015.03.0 20

Wollschlaeger, M., Sauter, T., \& Jasperneite, J. (2017). The Future of Industrial Communication: Automation Networks in the Era of the Internet of Things and Industry 4.0. IEEE Industrial Electronics Magazine, 11(1), 17-27. https://doi.org/10.1109/MIE.2017.2649104

Yang, A., Li, Y., Liu, C., Li, J., Zhang, Y., \& Wang, J. (2019). Research on logistics supply chain of iron and steel enterprises based on block chain technology. Future Generation Computer Systems, 101, 635-645. https://doi.org/10.1016/j.future.2019.07.008

Yli-Huumo, J., Ko, D., Choi, S., Park, S., \& Smolander, K. (2016). Where Is Current Research on Blockchain Technology?-A Systematic Review. PLoS ONE, 11(10). https://doi.org/10.1371/journal.pone.0163477

Zhang, Q., \& Cao, M. (2018). Exploring antecedents of supply chain collaboration: Effects of culture and interorganizational system appropriation. International Journal of Production Economics, 195, 146-157. https://doi.org/https://doi.org/10.1016/j.ijpe.2017.10.0 14

Zheng, Z., Xie, S., Dai, H.-N., Chen, X., \& Wang, H. (2018). Blockchain challenges and opportunities: a survey. International Journal of Web and Grid Services, 14(4), 352-375. https://doi.org/10.1504/ijwgs.2018.095647

Zheng, Z., Xie, S., Dai, H., Chen, X., \& Wang, H. (2017). An Overview of Blockchain Technology: Architecture, Consensus, and Future Trends Symposium conducted at the meeting of the IEEE 6th International Congress on Big Data, Honolulu, Hawaii, USA. 
Zyskind, G., Nathan, O., \& Pentland, A. (2015, 21-22 May 2015). Decentralizing Privacy: Using Blockchain to Protect Personal Data Symposium conducted at the meeting of the 2015 IEEE Security and Privacy Workshops https://doi.org/10.1109/SPW.2015.27

Dr Michael Wang is currently a Lecturer in Logistics Engineering at Faculty of Engineering Technology \& Science, Higher Colleges of Technology, Abu Dhabi, United Arab Emirates. Prior to this, he was a Lecturer in Supply Chain Management at Department of Business Information System, the Auckland University of Technology, New Zealand. Michael received his $\mathrm{PhD}$ from RMIT University, Melbourne, Australia. He has more than 10 years' business research and management experience in New Zealand and Australia. His main research areas are supply chain management, international logistics, sustainability, supply chain uncertainty and risk, logistics innovation, supply chain capability, urban freight transport and logistics.

Dr Yong Wu is currently a Senior Lecturer in the Department of Business Strategy and Innovation at Griffith University, Australia. He obtained his PhD from Nanyang Technological University, Singapore and his Master's Degree from Nanjing University of Aeronautics and Astronautics, China. He teaches in the area of logistics and supply chain management and his research interests include supply chain modeling, optimization and simulation, operations research to improve logistics activities, and global optimization and computational intelligence for problems in logistics and supply chain management and related areas. He is a member of the Institute for Operations Research and the Management Sciences (INFORMS).

Mr Bruce Chen is currently a Lecturer in the IT faculty at Monash University, Australia. He completed his Master's degree in master of business information from Monash University. His teaching areas are Artificial intelligence and Machine learning and research areas are Automation, Computer Vision and IOT. Currently, he is also a lead risk analytic in Latitude Financial Services.

Ms Melissa Evans is currently the Science Leader for Forest Informatics at Scion (New Zealand Forest Research Institute Limited), New Zealand. Melissa leads a team of scientists, engineers and researchers in the areas of data science, computer science, bioinformatics, remote sensing, GIS and Unmanned Aerial Vehicles. Her research interests include Augment reality, IOT, Blockchain, robotics, information and data systems and related areas. Outside of the science domain, Melissa has over 20 years' experience in business management and small business directorship/ownership 